\title{
Article \\ 3D Co-Ni-C Network from Milk as Competitive Bifunctional Catalysts for Methanol and Urea Electrochemical Oxidation
}

\author{
Dana Ao, Yue Shi, Shuyuan Li, Ying Chang, Aiju Xu, Jingchun Jia * and Meilin Jia
}

Inner Mongolia Key Laboratory of Green Catalysis and Inner Mongolia Collaborative Innovation Center for Water Environment Safety, College of Chemistry and Environmental Science, Inner Mongolia Normal University, Hohhot 010022, China; aodn@mails.imnu.edu.cn (D.A.); shiy@mails.imnu.edu.cn (Y.S.); lisy@mails.imnu.edu.cn (S.L.); changying@imnu.edu.cn (Y.C.); xuaj@imnu.edu.cn (A.X.); jml@imnu.edu.cn (M.J.)

* Correspondence: jjc@imnu.edu.cn; Tel.: +86-471-4392124

check for updates

Citation: Ao, D.; Shi, Y.; Li, S.; Chang, Y.; Xu, A.; Jia, J.; Jia, M. 3D Co-Ni-C Network from Milk as Competitive Bifunctional Catalysts for Methanol and Urea Electrochemical Oxidation. Catalysts 2021, 11, 844. https:// doi.org/10.3390/catal11070844

Academic Editor: Vincenzo Baglio

Received: 7 June 2021

Accepted: 8 July 2021

Published: 14 July 2021

Publisher's Note: MDPI stays neutral with regard to jurisdictional claims in published maps and institutional affiliations.

Copyright: (c) 2021 by the authors. Licensee MDPI, Basel, Switzerland. This article is an open access article distributed under the terms and conditions of the Creative Commons Attribution (CC BY) license (https:// creativecommons.org/licenses/by/ $4.0 /)$.
Abstract: Methanol oxidation (MOR) and urea oxidation (UOR) have been considered for new types of fuel cells, but the lack of highly active nonnoble metal catalysts restricts such cells. A NiComodified biomass carbon (milk as the carbon source)-based catalyst with a 3D structure is synthesized by using salt templates. The results show that 3D-C-NiCo (1:1) exhibits excellent MOR and UOR properties with a potential of $1.33 \mathrm{~V}$ vs. RHE and $1.35 \mathrm{~V}$ vs. RHE at $10 \mathrm{~mA} \mathrm{~cm}^{-2}$, respectively. MOR and UOR reactions not only can replace the oxygen evolution reaction (OER) in consumption of electrolytic water but also can effectively degrade wastewater pollution rich in methanol and urea.

Keywords: nonnoble catalyst; methanol oxidation; urea oxidation

\section{Introduction}

The search for new green energy is an effective way to address the increasingly serious energy crisis and environmental issues [1,2]. Novel fuel cells, such as methanol fuel cells (DMFCs) and urea fuel cells (DUFCs), have attracted extensive interest from scientists due to their high energy density and official sources [3-5]. Methanol oxidation (MOR) and urea oxidation (UOR) are the key reactions of these fuel cells [5,6]. In the preparation process of hydrogen energy, the reaction kinetics of hydrogen evolution from electrolytic water are slow; the overpotential required for the reaction is large, and the total energy consumption of the reaction is high [7]. Therefore, the reaction rate of hydrogen evolution from the cathode is limited to a certain extent. The MOR and UOR replacing the oxygen evolution reaction (OER) could significantly decrease the total energy consumption of the water electrolysis reaction and accelerate the hydrogen evolution reaction [8,9]. MOR and UOR can also alleviate the pollution of methanol wastewater produced in the organic process $[10,11]$.

Pt-based materials have good properties in MORs and UORs, but they are difficult to apply on a large scale because Pt-based materials are precious metals [4,12]. Therefore, nonnoble metals have been used to replace noble metal catalysts for MORs and UORs. In the last several years, nickel-based catalysts have been widely available for oxygen evolution reactions (OERs), hydrogen evolution reactions (HERs), UORs, and MORs [13-19]. Many experiments have shown that the performance of MORs or UORs could be improved by the combination of nickel-based catalysts with cobalt or other elements, such as 3D $\mathrm{NiCO}_{2} \mathrm{O}_{4}$ architectures [20], nickel phosphates [21], and $\mathrm{Mn}^{2+}$-doped $\mathrm{Ni}_{3} \mathrm{~S}_{2}$ [22]. There are some $\mathrm{Ni}$ and $\mathrm{Co}-$ based materials that exhibit excellent catalytic activity for MORs and UORs, which are shown in the Tables S1 and S2.

Because of the excellent oxidation properties of Ni, Co-based and alloy materials, we designed the use of salt templates and $\mathrm{Ni}$ and $\mathrm{Co}$ precursors after carbonization to prepare 3D structured NiCo alloy-modified carbon-based materials. At the same time, different proportions of catalysts were prepared by calcination at the same temperature. The catalyst with Ni:Co (1:1) has the best UOR and MOR performance. 


\section{Results and Discussion}

All catalysts were synthesized by calcining salt and milk, as shown in Figure 1a. It shows the SEM of the samples, indicating a 3D porous structure in Figure $1 \mathrm{~b}$. In Figure $1 \mathrm{~b}$ and Figure S1, the element distribution diagram of the sample contains $\mathrm{Co}$, $\mathrm{Ni}, \mathrm{P}, \mathrm{C}$, and N. 3D-C-CoNi (1:1) has a layered structure, showing a relatively thin state (Figure 1c). In transmission electron microscopy (TEM), the local structure information of the sample was observed, and the surface was porous (Figure 1d). The lattice structure of the sample can be clearly seen by high resolution transmission electron microscope (HR-TEM) characterization in Figure 1e. The NiCo is uniform distribution with the 3D carbon, and a clear structure is shown in the TEM (Figure 1c-e). The carbon layer is tightly combined with the metal to ensure good conductivity in 3D-C-NiCo (1:1) catalysts. The structural stripe is $0.211 \mathrm{~nm}$, corresponding to $\mathrm{CoNi}$ (111), which is the same as that reported in the literature $[23,24]$. Further characterization shows that the sample has a clear diffraction ring in Figure 1f, indicating that the CoNi alloy in the sample has a good crystalline state.

$\mathbf{a}$
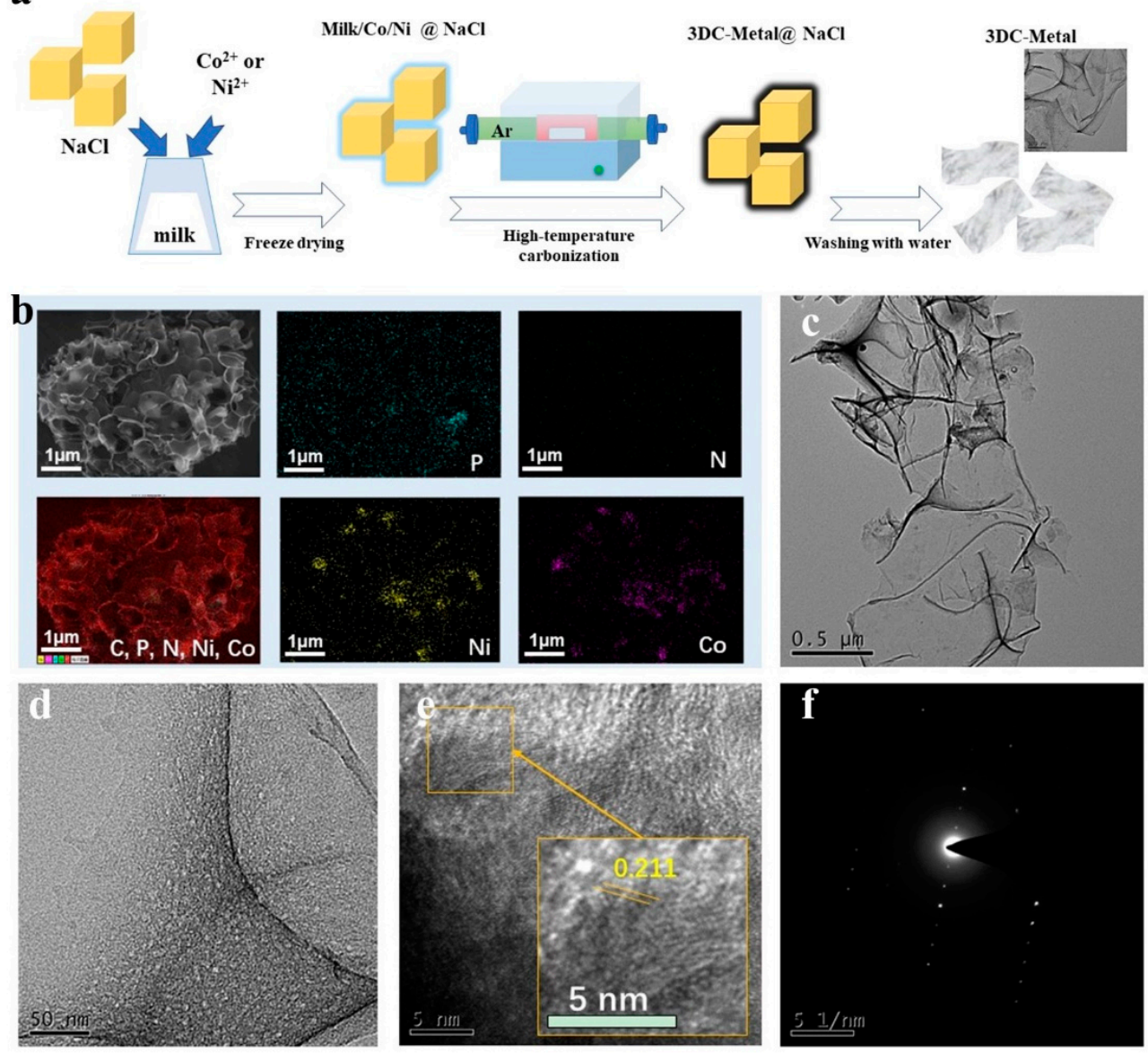

Figure 1. (a) Diagrammatic drawing of the synthetic process for 3D-C-metal, (b) SEM and elemental mappings, (c,d) TEM images of 3D-C-NiCo (1:1), (e) HR-TEM images of 3D-C-NiCo (1:1), and (f) SAED pattern of 3D-C-NiCo (1:1).

The X-ray powder diffraction (XRD) pattern of the catalyst (Figure 2a and Figure S2) shows diffraction peaks of the CoNi alloy at $44.5^{\circ}$ (111), 51.5 (200) and $76.0^{\circ}$ (220) [23]. It shows that 3D-C-CoNi (1:1) metal exists in the form of an alloy. The electronic structures of the elements in 3D-C-CoNi (1:1) were analyzed by X-ray photoelectron spectroscopy (XPS). In the full spectrum (Figure $2 \mathrm{~b}$ and Table S3), there were distinct $\mathrm{C}, \mathrm{N}, \mathrm{P}, \mathrm{Ni}$, and Co elements. The 284.80 and $286.30 \mathrm{eV}$ are graphene-like $\mathrm{C}$ and $\mathrm{C}$ in C-O, respectively (Figure S3). The phosphorus is rich in phospholipids of Milk, which could be doped in the 
carbonization process. In the high-resolution graph, the binding energy corresponds to zero valence $\mathrm{Ni}$ at $855.64\left(\mathrm{Ni} 2 \mathrm{p}_{3 / 2}\right)$ and $872.99 \mathrm{eV}\left(\mathrm{Ni} 2 \mathrm{p}_{1 / 2}\right)$, while the binding energy is fitted for $\mathrm{Ni} 2 \mathrm{p}_{3 / 2}(861.95 \mathrm{eV})$ and Ni $2 \mathrm{p}_{1 / 2}(879.70 \mathrm{eV})$ in $\mathrm{Ni}^{2+}$ (Figure 2c) [24]. The binding energy at $780.93 \mathrm{eV}$ is the zero valence state of $\mathrm{Co}$ (Figure 2d), while the 786.49 and $796.74 \mathrm{eV}$ are fitting peaks, indicating $\mathrm{Co}_{2} \mathrm{p}_{3 / 2}$ and $2 \mathrm{p}_{1 / 2}$ for $\mathrm{C}_{\mathrm{O}}{ }^{2+}$, respectively [24]. In Figure $2 \mathrm{e}$, it reveals the presence of four $\mathrm{N}$ species in 3D-C-CoNi (1:1), namely, pyridine nitrogen $(398.42 \mathrm{eV})$, metal-coordinated $\mathrm{N}(399.27 \mathrm{eV})$, pyrrole nitrogen $(400.82 \mathrm{eV})$, and oxidized nitrogen $(403.21 \mathrm{eV})$; moreover, $\mathrm{P}-\mathrm{C}(133.27 \mathrm{eV})$ and $\mathrm{P}-\mathrm{O}(134.42 \mathrm{eV})$ were confirmed to be present in the P2p spectrum $[25,26]$. Pyridine-N, metal-N, and graphite-N of 3D-C-CoNi (1:1) are the active centers, which potentially improve its electrocatalytic activity.
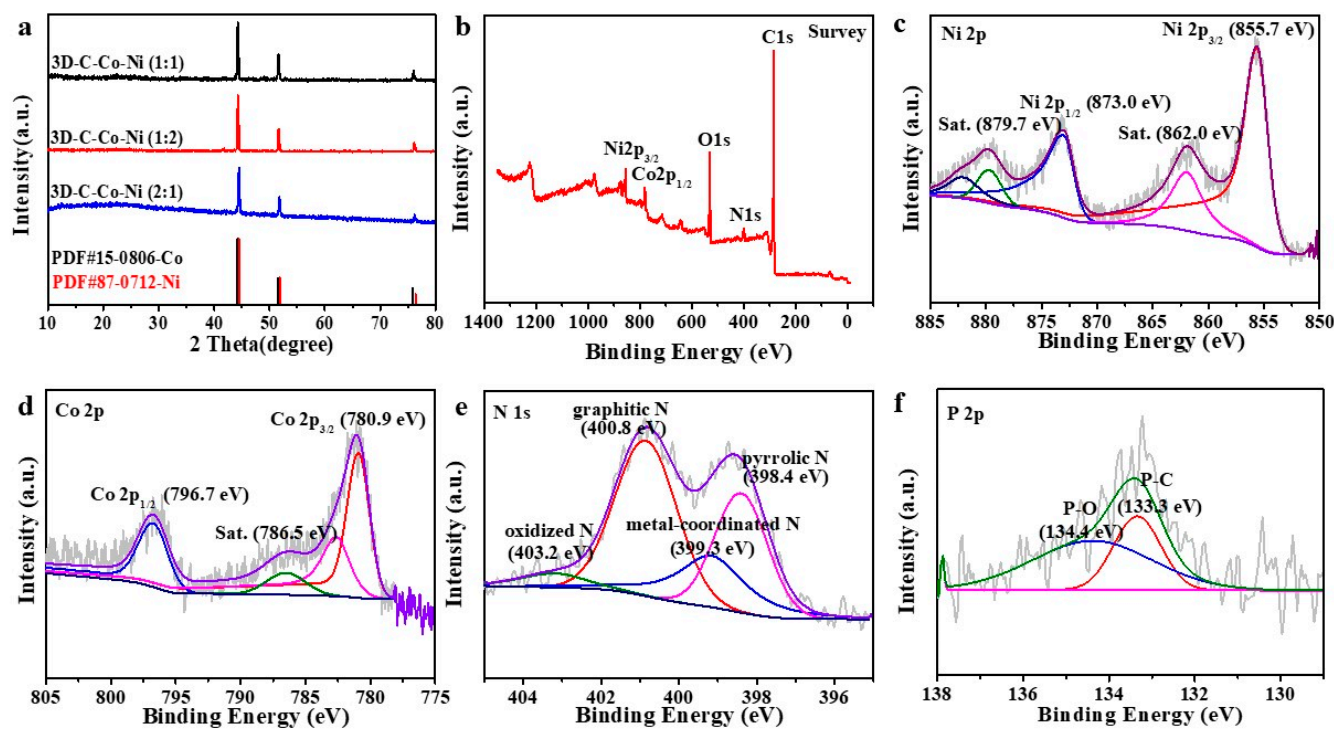

Figure 2. (a) XRD pattern; (b) survey XPS spectrum; and (c) Co2p, (d)

(d) Ni2p, (e) N1s, and (f) P2p spectra.

The cyclic voltammetry (CV) and linear sweep voltammetry (LSV) curves measured in different electrolytes are exhibited in Figure 3a,b. The potential of the OER for 3D-C-CoNi (1:1) in $1 \mathrm{M} \mathrm{KOH}$ electrolyte is $1.55 \mathrm{~V}$ vs. RHE (@10 $\mathrm{mA} \mathrm{cm}^{-2}$ ). The 3D-C-CoNi (1:1) has a potential of $1.35 \mathrm{~V}$ vs. RHE (@10 mA cm${ }^{-2}$ ), which indicates that UOR could proceed smoothly. The comparison of LSV curves for urea oxidation performance of all catalysts calcined at different proportions $(\mathrm{Co}, \mathrm{Ni})$ is shown in Figure $3 \mathrm{c}$. The results show that the overpotential of 3D-C-CoNi (1:1) is the lowest at the same current density, indicating that 3D-C-CoNi (1:1) has the best urea oxidation performance in Figure $3 \mathrm{c}$ and Figure S4a. The 3D-C-CoNi (1:1) electrocatalyst shows fast UOR reaction kinetics because of the smaller Tafel slopes (128 $\mathrm{mV} \mathrm{dec}^{-1}$ ) compared to other samples (Figure 3d).

To study the ECSA, we also measured the $\mathrm{C}_{\mathrm{dI}}$ of 3D-C-CoNi (1:1) in Figures S5 and S6, which is slightly higher than that of other catalysts, indicating that the active site exposure was caused by metal-coordinated $\mathrm{N}$ and nanoalloyed cobalt-nickel. Electrochemical impedance spectroscopy (EIS) was tested (@ $1.4 \mathrm{~V}$ ) in Figure 3e. The results show that 3D-C-CoNi (1:1) has the fastest catalytic kinetic process because of the smallest semicircle radius (Figure 3e). The increase in surface area and the 3D structure of 3D-C-CoNi (1:1) are conducive to the function of active sites, and the structure also accelerates the charge transfer in UOR performance. A stability test of urea oxidation performance is shown in Figure 3f. Significantly, 3D-C-CoNi (1:1) showed highly enhanced catalytic activity for UOR, but 3D-C-CoNi (1:2) could stably catalyze urea oxidation for $4000 \mathrm{~s}$, which means that the increase in nickel content could enhance the catalytic performance. 

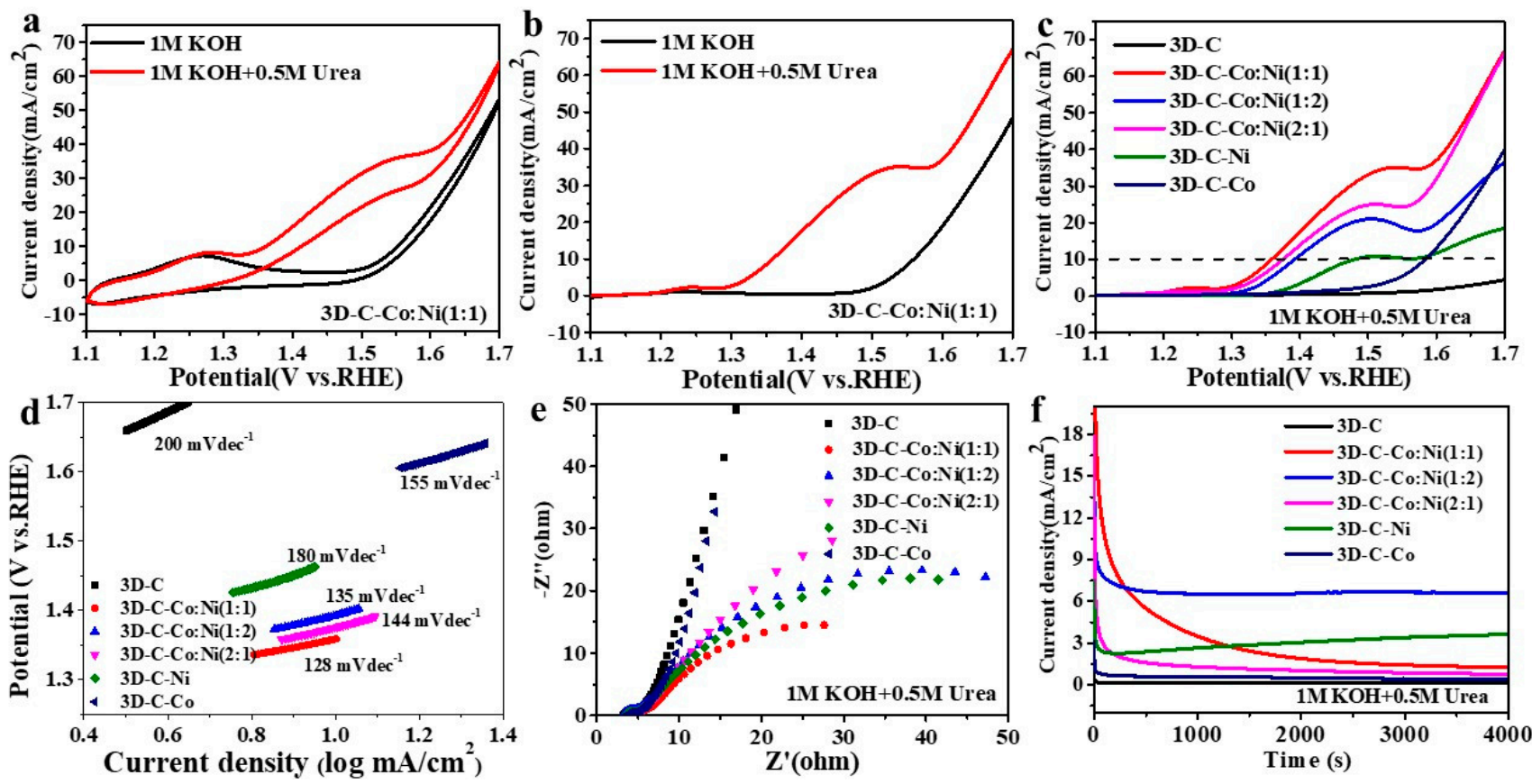

Figure 3. (a) CV and (b) LSV profiles of 3D-C-NiCo (1:1) for UOR with or without urea, (c) LSV profiles for different catalysts, (d) the Tafel slope from LSV curves, (e) Nyquist plots of different catalysts, and (f) the stability test of 3D-C-NiCo (1:1) for UOR.

Figure $4 \mathrm{a}, \mathrm{b}$ shows the LSV and CV diagrams of 3D-C-CoNi in $1 \mathrm{M} \mathrm{KOH} / 0.5 \mathrm{M} \mathrm{MeOH}$. The anodic peak current increased significantly, indicating that 3D-C-CoNi (1:1) has MOR performance. The onset potential (1.31 V vs. RHE) of 3D-C-CoNi (1:1) is lower than the other catalysts in Figure $4 c$ and Figure S4b. The potential of 3D-C-CoNi (1:1) is $1.33 \mathrm{~V}$ vs. RHE for MOR at $10 \mathrm{~mA} \mathrm{~cm}{ }^{-2}$. The 3D-C-CoNi (1:1) electrocatalyst shows a small Tafel slope of $106 \mathrm{mV} \mathrm{dec}^{-1}$ compared to the other samples, which indicates fast MOR reaction kinetics (Figure 4d).
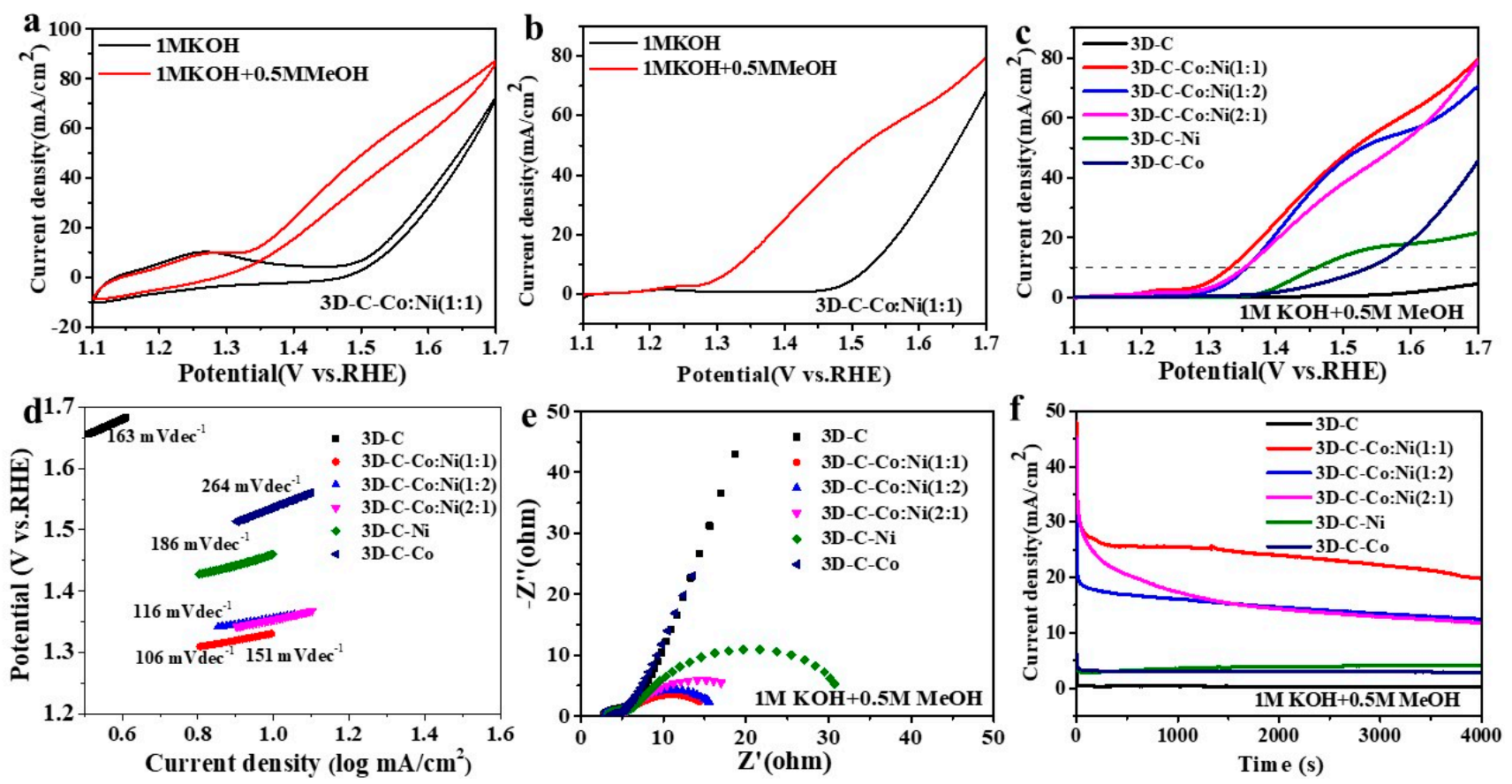

Figure 4. (a) CV and (b) LSV profiles of 3D-C-NiCo (1:1) for MOR with or without MOH, (c) LSV profiles for different catalysts, (d) the Tafel slope from LSV curves, (e) Nyquist plots of different catalysts, and (f) the stability test of 3D-C-NiCo (1:1) for MOR. 
The EIS of MOR (at $1.4 \mathrm{~V}$ vs. RHE) was measured in Figure 4e. All semicircles of the samples have the smallest radius, and the semicircles have the largest radius. A small semicircle radius implies that the charge transfer impedance for methanol oxidation is small, which may be related to the synergism between 3D carbon and CoNi to accelerate charge transfer [27]. The electrochemical stability of 3D-C-CoNi (1:1) is also a very significant factor to be evaluated by chronoamperometry, as shown in Figure 4f. The results show that 3D-C-CoNi (1:1) has the highest oxidation performance. The current density at $4000 \mathrm{~s}$ was $20.2 \mathrm{~mA} \mathrm{~g}^{-1}$, which was 1.9- and 2.1-fold greater than that observed for 3D-C-CoNi (1:2) and 3D-C-CoNi (2:1), respectively.

\section{Experimental Part}

\subsection{Experimental Materials and Preparation of the Catalysts}

Milk (from cow) was produced at Inner Mongolia Shenniu Emulsion Development Co., Ltd. (Hohhot, China). Deionized water was homemade in the laboratory. All experimental reagents were used directly without further treatment, and detailed information is provided in the Supporting Information.

We weighed $10 \mathrm{~g}$ of $\mathrm{NaCl}, 11 \mathrm{~g}$ of milk and $0.4441 \mathrm{~g}$ of $\mathrm{CoCl}_{2} \cdot 6 \mathrm{H}_{2} \mathrm{O}$ with an analytical balance. The above materials were mixed evenly and dissolved with deionized $(40 \mathrm{~mL})$ water. The mixture was lyophilized in liquid nitrogen and dry a freeze-drying machine for $24 \mathrm{~h}$ with an internal temperature of $-50^{\circ} \mathrm{C}$ and a vacuum of $19 \mathrm{~Pa}$. The above samples were heated at $5{ }^{\circ} \mathrm{C} / \mathrm{min}$ and kept $800{ }^{\circ} \mathrm{C}$ for $2 \mathrm{~h}$, and the above operation was carried out in an $\mathrm{Ar}$ atmosphere $\left(40 \mathrm{~cm}^{3} / \mathrm{min}\right)$ in a tubular furnace. Finally, the $\mathrm{NaCl}$ was washed off by centrifugation with deionized water, and the samples were dried for $12 \mathrm{~h}$. Samples were collected and named 3D-C-Co. Samples with different mass ratios of $\mathrm{Ni}$ and Co (denoted as 3D-C-Co:Ni (1:2), 3D-C-Co:Ni (2:1), and 3D-C-Co:Ni (1:1) and 3D-C-Ni were prepared in the same way as 3D-C-Co. Figure 1 a shows the synthetic process of the material. More detailed information is shown in the Supporting Information.

\subsection{Characterizations of the Catalysts}

XRD was performed using a Rigaku UItima IV (Tokyo, Japan) with $\mathrm{Cu} \mathrm{K} \alpha$ radiation $(\lambda=1.5406 \AA)$ at $40 \mathrm{kV}$ and $40 \mathrm{~mA}$. Field emission transmission electron microscopy (FETEM) was performed using a Tecnai G2 F20 (Hillsboro, OR, USA) with a voltage of 200 $\mathrm{kV}$, and $\mathrm{Cu}$ grids served as the substrate. XPS was performed using an ESCALAB 250Xi (Waltham, MA, USA), and Al was used as the anode XR50 source (hv = $1486.6 \mathrm{eV})$ at $150 \mathrm{~W}$.

\subsection{Electrochemical Test}

The three-electrode system was using a CHI 760E (Shanghai, China) electrochemical workstation with $\mathrm{Pt}$ mesh, $\mathrm{Hg} / \mathrm{HgO}$ and carbon paper $(\mathrm{CP})$. The catalyst slurry was a mixture of water, ethanol and Nafion prepared by ultrasonication for $30 \mathrm{~min}$ at a volume ratio of 1:9:10. The catalyst and slurry were prepared at a ratio of $5 \mathrm{mg}$ per $1 \mathrm{~mL}$ and treated with ultrasonication for $30 \mathrm{~min}$. Twenty-five milliliters of the catalyst slurry was evenly coated on carbon paper $(0.5 \mathrm{~cm} \times 0.5 \mathrm{~cm})$, and the catalyst load was $0.5 \mathrm{mg} \mathrm{cm}^{-2}$.

\section{Conclusions}

The results show that 3D-C-NiCo (1:1) is an inexpensive, efficient, and persistent catalyst for MOR and UOR with a potential of 1.33 and $1.35 \mathrm{~V}$ vs. RHE at $10 \mathrm{~mA} \mathrm{~cm}{ }^{-2}$. The high performance of $3 \mathrm{D}-\mathrm{C}-\mathrm{NiCo}(1: 1)$ is due to the three-dimensional and nanocrystalline composite structure, thus providing more active sites for the reaction. These kinds of nonnoble metal catalysts provide a new method for MOR and UOR in fuel cells, as well as the degradation of organic pollutants and the reduction of potential water decomposition.

Supplementary Materials: The following are available online at https:/ / www.mdpi.com/article/ 10.3390/catal11070844/s1, Figure S1: EDS of 3D-C-NiCo (1:1), Figure S2: XRD pattern of different catalysts, Figure S3: C1s spectrum of 3D-C-NiCo (1:1), Figure S4: LSV profiles for different catalysts 
(3D-C-NiCo (1:1), 3D-C-NiCo (1:1)-from protein, 3D-C-NiCo (1:1)-from fat, 3D-C-NiCo (1:1)-from camel milk, and 3D-C-NiCo (1:1)-from goat milk) with $1 \mathrm{M} \mathrm{KOH} / 0.5 \mathrm{M}$ Urea (a), and $1 \mathrm{M} \mathrm{KOH} /$ $0.5 \mathrm{M} \mathrm{MeOH}$ (b), Figure S5: Double-layer capacitance for (a) 3D-C, (b) 3D-C-Ni:Co(1:1), (c) 3D-C$\mathrm{Ni} \mathrm{Co}(1: 2)$, (d) 3D-C-Ni, (e) 3D-C-Co, and (f) 3D-C-Ni in $1 \mathrm{M} \mathrm{KOH}$, Figure S6: Determination of double-layer capacitance over a range of scan rates, Table S1: The MOR performance, Table S2: The UOR performance, Table S3: Content of different element in 3D-C-NiCo (1:1).

Author Contributions: Conceptualization, J.J. and Y.C.; methodology, J.J. and Y.C.; formal analysis, D.A.; investigation, D.A., Y.S. and S.L.; resources, J.J., Y.C., A.X. and M.J.; writing-original draft preparation, D.A., Y.S., J.J. and Y.C.; writing-review and editing, D.A., Y.S., J.J. and Y.C.; supervision, J.J.; All authors have read and agreed to the published version of the manuscript.

Funding: This research was funded by Collaborative Innovation Cultivating Center for Water Environment Security of Inner Mongolia Autonomous Region China (XTCX003), Science and Technology Program of Inner Mongolia Autonomous Region, China (Grant No. 2020GG0010), and the Research Foundation for Advanced Talents of Inner Mongolia Normal University (No.2018YJRC012, 2018YJRC001).

Acknowledgments: The authors thank Sagala for discussion.

Conflicts of Interest: The authors declare no competing financial interest.

\section{References}

1. Tetteh, E.B.; Lee, H.Y.; Shin, C.H.; Kim, S.H.; Ham, H.C.; Tran, T.N.; Jang, J.H.; Yoo, S.J.; Yu, J.S. New PtMg alloy with durable electrocatalytic performance for oxygen reduction reaction in proton exchange membrane fuel cell. ACS Energy Lett. 2020, 5, 1601-1609. [CrossRef]

2. Tong, W.; Forster, M.; Dionigi, F.; Dresp, S.; Sadeghi Erami, R.; Strasser, P.; Cowan, A.J.; Farràs, P. Electrolysis of low-grade and saline surface water. Nat. Energy 2020, 5, 367-377. [CrossRef]

3. Ma, Y.; Yin, L.; Yang, T.; Huang, Q.; He, M.; Zhao, H.; Zhang, D.; Wang, M.; Tong, Z. One-pot synthesis of concave platinum-cobalt nanocrystals and their superior catalytic performances for methanol electrochemical oxidation and oxygen electrochemical reduction. ACS Appl. Mater. Interfaces 2017, 9, 36164-36172. [CrossRef]

4. Zhu, B.; Liang, Z.; Zou, R. Designing advanced catalysts for energy conversion based on urea oxidation reaction. Small 2020, 16, e1906133. [CrossRef]

5. Forslund, R.P.; Alexander, C.T.; Abakumov, A.M.; Johnston, K.P.; Stevenson, K.J. Enhanced electrocatalytic activities by substitutional tuning of nickel-based ruddlesden-popper catalysts for the oxidation of urea and small alcohols. ACS Catal. 2019, 9, 2664-2673. [CrossRef]

6. Wisniewska, J.; Sobczak, I.; Ziolek, M. The effect of the calcium dopant on the activity and selectivity of gold catalysts supported on SBA-15 and Nb-containing SBA-15 in methanol oxidation. Catal. Sci. Technol. 2021, 11, 2242-2260. [CrossRef]

7. Zhao, B.; Liu, J.; Xu, C.; Feng, R.; Sui, P.; Luo, J.-X.; Wang, L.; Zhang, J.; Luo, J.-L.; Fu, X.-Z. Interfacial engineering of $\mathrm{Cu}_{2} \mathrm{Se}_{\mathrm{C}} \mathrm{Co}_{3} \mathrm{Se}_{4}$ multivalent hetero-nanocrystals for energy-efficient electrocatalytic co-generation of value-added chemicals and hydrogen. Appl. Catal. B 2021, 285, 119800. [CrossRef]

8. He, L.; Huang, S.; Liu, Y.; Wang, M.; Cui, B.; Wu, S.; Liu, J.; Zhang, Z.; Du, M.J. Multicomponent Cog ${ }_{8} @ M_{0} S_{2}$ nanohybrids as a novel trifunctional electrocatalyst for efficient methanol electrooxidation and overall water splitting. Colloid Interface Sci. 2021, 586, 538-550. [CrossRef] [PubMed]

9. Zhao, B.; Liu, J.; Xu, C.; Feng, R.; Sui, P.; Wang, L.; Zhang, J.; Luo, J.L.; Fu, X.Z. Hollow NiSe nanocrystals heterogenized with carbon nanotubes for efficient electrocatalytic methanol upgrading to boost hydrogen co-production. Adv. Funct. Mater. 2020, 31, 2008812. [CrossRef]

10. Jia, J.; Zhao, L.; Chang, Y.; Jia, M.; Wen, Z. Understanding the growth of NiSe nanoparticles on reduced graphene oxide as efficient electrocatalysts for methanol oxidation reaction. Ceram. Int. 2020, 46, 10023-10028. [CrossRef]

11. Zhao, L.; Chang, Y.; Jia, M.; Jia, J.; Wen, Z.J. Monodisperse $\mathrm{Ni}_{0.85}$ Se nanocrystals on $\mathrm{rGO}$ for high-performance urea electrooxidation. Alloys Compd. 2021, 852, 156751. [CrossRef]

12. Zhao, F.; Ye, J.; Yuan, Q.; Yang, X.; Zhou, Z. Realizing a CO-free pathway and enhanced durability in highly dispersed Cu-doped PtBi nanoalloys towards methanol full electrooxidation. J. Mater. Chem. A 2020, 8, 11564-11572. [CrossRef]

13. Zheng, S.; Zheng, Y.; Xue, H.; Pang, H. Ultrathin nickel terephthalate nanosheet three-dimensional aggregates with disordered layers for highly efficient overall urea electrolysis. Chem. Eng. J. 2020, 395, 125166. [CrossRef]

14. Xu, X.; Du, P.; Guo, T.; Zhao, B.; Wang, H.; Huang, M. In situ grown Ni phosphate@ $\mathrm{Ni}_{12} \mathrm{P}_{5}$ nanorod arrays as a unique core-shell architecture: Competitive bifunctional electrocatalysts for urea electrolysis at large current densities. ACS Sustain. Chem. Eng. 2020, 8, 7463-7471. [CrossRef]

15. Xu, H.; Ye, K.; Zhu, K.; Gao, Y.; Yin, J.; Yan, J.; Wang, G.; Cao, D. Transforming carnation-shaped MOF-Ni to Ni-Fe prussian blue analogue derived efficient bifunctional electrocatalyst for urea electrolysis. ACS Sustain. Chem. Eng. 2020, 8, 16037-16045. [CrossRef] 
16. Wu, N.; Zhai, M.; Chen, F.; Zhang, X.; Guo, R.; Hu, T.; Ma, M. Nickel nanocrystal/nitrogen-doped carbon composites as efficient and carbon monoxide-resistant electrocatalysts for methanol oxidation reactions. Nanoscale 2020, 12, 21687-21694. [CrossRef]

17. Liu, S.; Hu, Z.; Wu, Y.; Zhang, J.; Zhang, Y.; Cui, B.; Liu, C.; Hu, S.; Zhao, N.; Han, X.; et al. Dislocation-strained IrNi alloy nanoparticles driven by thermal shock for the hydrogen evolution reaction. Adv. Mater. 2020, 32, e2006034. [CrossRef]

18. Ma, Y.; Dong, X.; Wang, R.; Bin, D.; Wang, Y.; Xia, Y. Combining water reduction and liquid fuel oxidization by nickel hydroxide for flexible hydrogen production. Energy Storage Mater. 2018, 11, 260-266. [CrossRef]

19. Liang, Q.; Zhong, L.; Du, C.; Zheng, Y.; Luo, Y.; Xu, J.; Li, S.; Yan, Q. Mosaic-structured cobalt nickel thiophosphate nanosheets incorporated N-doped carbon for efficient and stable electrocatalytic water splitting. Adv. Funct. Mater. 2018, 28, 1805075. [CrossRef]

20. Ranjani, M.; Senthilkumar, N.; Gnana Kumar, G.; Manthiram, A. 3D flower-like hierarchical $\mathrm{NiCo}_{2} \mathrm{O}_{4}$ architecture on carbon cloth fibers as an anode catalyst for high-performance, durable direct urea fuel cells. J. Mater. Chem. A 2018, 6, 23019-23027. [CrossRef]

21. Khalaf, M.M.; Abd El-Lateef, H.M.; Touny, A.H.; Saleh, M.M.; Mohamed, I.M.A. Electrocatalytic performance of inorganic nanoflakes nickel phosphates under adjusted synthetic parameters towards urea and methanol oxidation in alkaline media. Microchem. J. 2021, 163, 105901. [CrossRef]

22. Yang, H.; Yuan, M.; Sun, Z.; Wang, D.; Lin, L.; Li, H.; Sun, G. In situ construction of a $\mathrm{Mn}^{2+}$-doped $\mathrm{Ni}_{3} \mathrm{~S}_{2}$ electrode with highly enhanced urea oxidation reaction rerformance. ACS Sustain. Chem. Eng. 2020, 8, 8348-8355. [CrossRef]

23. Xie, Y.; Feng, C.; Guo, Y.; Li, S.; Guo, C.; Zhang, Y.; Wang, J. MOFs derived carbon nanotubes coated CoNi alloy nanocomposites with $\mathrm{N}$-doped rich-defect and abundant cavity structure as efficient trifunctional electrocatalyst. Appl. Surf. Sci. 2021, 536, 147786. [CrossRef]

24. Zhu, C.; Yang, W.; Di, J.; Zeng, S.; Qiao, J.; Wang, X.; Lv, B.; Li, Q. CoNi nanoparticles anchored inside carbon nanotube networks by transient heating: Low loading and high activity for oxygen reduction and evolution. J. Energy Chem. 2021, 54, 63-71. [CrossRef]

25. Ahn, S.H.; Klein, M.J.; Manthiram, A. 1D Co-and N-doped hierarchically porous carbon nanotubes derived from bimetallic metal organic framework for efficient oxygen and tri-iodide reduction reactions. Adv. Energy Mater. 2017, 7, 1601979. [CrossRef]

26. Najam, T.; Shah, S.S.A.; Ding, W.; Jiang, J.; Jia, L.; Yao, W.; Li, L.; Wei, Z. An efficient anti-poisoning catalyst against $\mathrm{SO}_{\mathrm{x}}, \mathrm{NO}_{\mathrm{x}}$ and $\mathrm{PO}_{\mathrm{x}}$ : P, N-Doped carbon for oxygen reduction in acidic media. Angew. Chem. Int. Ed. 2018, 57, 15101-15106. [CrossRef]

27. Pham, T.N.; Samikannu, A.; Tesfalidet, S.; Wågberg, T.; Mikkola, J.P. NiCo Nanoneedles on 3D Carbon Nanotubes/Carbon Foam Electrode as an Efficient Bi-Functional Catalyst for Electro-Oxidation of Water and Methanol. Catalysts 2021, 11, 500. [CrossRef] 